\title{
A Escola de Qualidade para Todos: Abrindo as Camadas da Cebola ${ }^{1}$
}

\author{
Candido Alberto Gomes
}

\section{RESUMO}

A pesquisa educacional apresenta hoje abundantes constatações sobre como construir uma escola de qualidade para todos. Este trabalho se concentra em aspectos selecionados das diferenças entre escolas e dentro das escolas, com base na literatura nacional e internacional, embora mencionando a importância das origens sociais dos alunos, gestão educacional, avaliação e trajetórias curriculares. A estrutura peculiar dos sistemas educacionais se assemelha a uma cebola, com sucessivas camadas que influenciam a aprendizagem. Assim, se destacam despesas, instalações, tempo letivo, professores, clima e gestão escolares, efeitos dos colegas, alocação da matrícula e do espaço, ações que contribuem para a efetividade na sala de aula e a formação de turmas. Portanto, é possível atuar sobre os fatores intra-escolares, no seu âmbito de influência, que têm papel mais amplo nos países em desenvolvimento.

Palavras-chave: Sociologia da educação. Economia da educação. Sociologia da escola. Democratização da educação. Professores. Sociedade dos adolescentes. Clima escolar. Gestão escolar.

\section{ABSTRACT Qualified school for all: opening the peels of the onion.}

Educational research presents numerous findings today on how to build a qualified school for all. This paper recognizes the importance of the social origins of the students, educational management, evaluation, curricular organization etc. However, if focuses on selected features related to the differences among and within schools, on the basis of the national and international literature. Considering that the peculiar structure of the educational systems is similar to an onion, with its successive peels, this work analyses factors affecting learning, such as expenditure, facilities and equipment, time, teachers, school climate and management, peer

${ }^{1}$ O tema deste artigo será tratado com maior profundidade no livro do autor, A educação em novas perspectivas sociológicas (4. ed. rev. e ampl. São Paulo: EPU, no prelo). 
effects, enrollment procedures, space management, student grouping, and other factors that affect effectively in the classroom. Therefore, it is possible to shape such a school, particularly in developing countries, where its impact is stronger than in developed countries.

Keywords: Sociology of education. Economics of education. Sociology of the school. Educational democratization. Teachers. Adolescent society. School climate. School management.

\section{RESUMEN}

\section{La escuela de calidad para todos: abriendo las cáscaras de la cebolla.}

La investigación educativa presenta hoy una gran cantidad de resultados capaces de orientar la construcción de una escuela de calidad para todos. Este trabajo hace la reseña de factores seleccionados de las diferencias entre las escuelas y en el interior de ellas, según la literatura nacional y internacional. Aunque reconozca la importancia de los orígenes sociales de los estudiantes, de la gestión de los sistemas educativos, de la evaluación y de las diferentes trayectorias curriculares, este trabajo considera la estructura particular de los sistemas, semejante a una cebolla, con sus successivas cáscaras y sus relaciones con el aprendizaje. De este modo, destaca los gastos, instalaciones y recursos, tiempo, magistério, clima y gestión de las escuelas, efectos de los compañeros, administración de la matrícula y de las relaciones espaciales y agrupamiento de secciones. Así, es posible actuar sobre los factores internos de la escuela, que tiene un rol más influyente en los países en desarrollo.
Palabras clave: Sociología de la educación. Economía de la educación. Sociología de la escuela. Democratización de la educación. Magisterio. Sociedade de los adolescentes. Clima escolar. Gestión escolar.

Um dos maiores desafios da história da educação é organizar uma escola que seja, ao mesmo tempo, de qualidade e democrática, isto é, que não ofereça aos pobres uma escolaridade pobre, mas que efetivamente consiga que os alunos, mesmo socialmente desprivilegiados, aprendam. Muito se pode extrair da literatura internacional sobre o que fazer e não fazer aos níveis dos sistemas educacionais e das escolas. Evidentemente, é preciso considerar primeiro as origens sociais dos alunos. $\bigcirc$ peso das variáveis envolvidas é muito expressivo, embora a escola, sobretudo nos países em desenvolvimento, tenha maior área de ação e não possa se omitir.

Além das origens sociais dos alunos, existem características macro-educacionais ponderáveis que condicionam a qualidade e o grau de democratização das escolas. Neste nível temos as características da gestão, como - grau de centralização ou descentralização incidente sobre cada comportamento dos atores; o modo como está organizada a avaliação do sistema, destacando-se como os resultados são divulgados (por exemplo, ao público e por escola ou não) e como são trabalhados; o financiamento público ou privado, o papel de cada um deles e a criação de mecanismos de mercado no setor público; as trajetórias curriculares, em especial se os alunos são classificados mais ou menos tarde e direcionados para ramos mais ou menos prestigiosos, como a educação profissional ou acadêmica; a organização em séries ou em ciclos, com diferentes possibilidades de avanço. 
A estrutura da escola e do sistema educacional foi por muito tempo comparada a uma caixa preta, que processava insumos e oferecia resultados à sociedade. Este modelo mais simples parece hoje incapaz de refletir a complexidade do real. Eles estão muito distantes de uma empresa, com estrutura piramidal, onde as ordens passam de escalão a escalão. Ao contrário, os fatos se sucedem diferentemente, de tal modo que uma metáfora útil seria a da cebola. De fato, o sistema educacional está dividido em camadas: primeiro, abrem-se as das diversas redes, depois de órgãos gestores regionais e locais; em seguida, as diferentes escolas e, nestas, as diversas turmas, com os seus variados professores e, por fim, os grupos de alunos, com adesão maior ou menor aos objetivos da escola. Desta forma, orientações e normas não passam com facilidade de uma para outra camada.

\section{Diferenças Entre as Escolas}

As avaliações internacionais têm evidenciado que as diferenças de rendimento discente são com freqüência tão amplas entre países quanto entre as escolas do mesmo país. Como as variáveis intra-escolares podem contribuir não para aumentar, mas para diminuir as disparidades de aproveitamento, ao mesmo tempo em que aumentam a sua média? Para além das origens sociais, focalizadas antes, como a escola pode melhor exercer o seu papel democratizador? Para além das origens sociais, focalizadas antes, como a escola pode meIhor exercer o seu papel democratizador? - chamado efeito escola é avaliado nos países anglo-saxões em cerca de $7 \%$ da variância de nível dos alunos na sua língua materna ou matemática. Na França foi encontrado um efeito de $5 \%$ na variância do rendimento discente em matemática após quatro anos no collège (educação secundária inferior) e de $3 \%$ em francês. No entanto, estas são estimativas difíceis, realizadas com freqüência por exclusão. Segundo outro cálculo, o efeito escolar correspondia de 3 a $17 \%$ da variância dos resultados dos alunos no início do ensino secundário superior na França (MEURET, 2000). Considerando o grande peso das origens sociais dos discentes, estes números não são pequenos e ainda há que acrescentar os efeitos das diferenças de tratamento das escolas, isto é, os denominados efeitos turma e professor. Na América Latina o modelo de Casassus (2002) explicou, no total, até mais de dois terços da variância do aproveitamento em linguagem e matemática. $\bigcirc$ índice de status sociocultural explicou até 18,3\% das diferenças entre as escolas e quase $6 \%$ da variância dentro das escolas. Em face destes resultados e contrariando outras constatações, os efeitos escola e turma foram maiores. As diferenças dentro das escolas ficaram em torno de $8,0 \%$ e entre as escolas em cerca de $50,0 \%$ a $46,0 \%$. Num Continente em desenvolvimento, a escola tem um papel não só relevante, mas, por este modelo, além das expectativas.

Uma resenha seletiva das investigações, inclusive na América Latina, representa um ponto de partida para a reflexão sobre o chamado efeito escola e os fatores que o possibilitam. As pesquisas aqui incluídas são heterogêneas e correspondem a diversas orientações. A metodologia quantitativa de muitas delas, como as de Coleman e outros (1966) e Castro e outros (1984), tratando em termos simplificados, buscam verificar o impacto de vários preditores so- 
bre uma variável dependente, com maior freqüência o aproveitamento discente medido por testes padronizados. Com isso, é possível verificar o impacto de cada preditor, mantendo estáveis as demais variáveis incluídas (p. ex., o status socioeconômico), bem como construir modelos que, reunindo um conjunto de preditores, é capaz de explicar um percentual mais ou menos alto das variações da variável dependente, no caso, o rendimento dos alunos. Estas perspectivas, como outras, em face da complexidade do real, recortam determinados segmentos para focalizar, supondo a simplificação de certas áreas da realidade. Isto ocorre não por ingenuidade, mas por incontornável necessidade de fazer opções. No caso, para facilitar a análise, supõe-se que a escola seja uma "caixa preta", com um funcionamento de certo modo mecânico, conforme a metáfora antes indicada. Assim, calcula-se o impacto de livros didáticos e laboratórios sobre a aprendizagem, mas não se consegue conhecer com maior precisão como tais recursos são usados e se são usados efetivamente.

A sociologia das organizações tem dado uma contribuição importante, revelando a escola não como um tipo ideal de burocracia, que funciona de modo estritamente racional, à semelhança de um relógio, mas como organização flexivelmente articulada. Composta de salas de aula que se relacionam com uma unidade de atividades-meio (a administração), cada professor dispõe de relativa independência e invisibilidade na classe. Deste modo, decisões tomadas num segmento não são aplicadas automaticamente em outros (WEICK, 1976 apud COSTA, 1996). O mesmo vale para o conjunto relativamente frouxo das secretarias de educação, delegacias de ensino, escolas e salas de aula. Daí a necessidade de uma nova metáfora, a da cebola. Depois de abrir as camadas mais amplas do sistema educacional, é preciso estudar a casca da escola e, dentro dela, a camada da turma, do professor e do aluno, em diferentes âmbitos, relacionando-se entre si. Para captar esta realidade dinâmica e fugidia, os métodos qualitativos têm oferecido grandes luzes, com vantagens e limitações. Na vertente dos métodos quantitativos, um grande avanço está nos modelos de análise multinível de influências dispostas hierarquicamente em um âmbito ou nível dentro do outro (multilevel hierarchically nested layer models) (RIORDAN, 2004). Este é um tratamento estatístico que se aproxima da "cebola", abrindo uma camada após a outra e superando dificuldades da suposta visão da "caixa preta".

De modo geral, as evidências mostram que as escolas efetivas podem contribuir para que os alunos com vantagens socioculturais e escolares as aumentem e os demais reduzam as suas desvantagens (MORTIMORE, 1997). É claro que isto implica a necessidade de mecanismos compensatórios, como melhor pré-escola, apoio ao estudo fora da escola, ajuda financeira etc. Não se justifica, pois, um fatalismo pedagógico. A escola sozinha não poderá compensar a sociedade, contudo, quando atinge a efetividade, pode contribuir, nos limites da sua faixa de atuação, para diminuir as diferenças sociais. Então, que atributos são influentes para se constituir uma escola democrática e de qualidade?

\section{Despesas por aluno}

O que dizer de uma escola cuja despesa por aluno é de 80 dólares anuais e outra de 10 mil dólares anuais? A escola mais cara é necessariamente melhor? As pesquisas se dividem quanto ao impacto das despesas por aluno, umas apresentando relação sig- 
nificativa com o rendimento discente e outras não (FULLER, 1987; COHN; ROSSMILLER, 1987; HANUSHEK et al., 1994; SCHEERENS; BOSKER, 1997; SCHEERENS, 2000; WOESSMAN, 2004). Por outro lado, em termos gerais, constata-se uma certa tendência de, quanto mais alta a despesa por aluno, ser melhor o desempenho em vários indicadores educacionais (CEPAL; UNESCO, 2004). Isto significa que não existe uma relação automática entre o aumento da despesa e o aumento do rendimento discente, exatamente porque a intermediação passa pelos processos dentro da escola. $\bigcirc$ fato de haver mais dinheiro não significa que ele seja aplicado apropriadamente, antes depende de disputas na alocação de recursos para atender aos objetivos educacionais racionais (MARION; FLANIGAN, 2001). Portanto, a lição que se pode extrair é que o incremento de recursos deve estar vinculado a procedimentos que contribuam para melhorar a efetividade da educação.

\section{Instalações e recursos}

As instalações e recursos apresentam impacto relativamente pequeno ou moderado, sendo mais importantes dentre eles os recursos (biblioteca, livros didáticos, textos, etc.) e a utilização deles (SCHIEFELBEIN; SIMMONS, 1980; CASTRO et al., 1984; ROCHA, 1984; FULLER, 1987; COHN; ROSSMILLER, 1987; ARMITAGE et al., 1986; COSTA, 1990; WOESSMAN, 2004). Segundo Casassus (2002), na América Latina os materiais didáticos alcançaram maior impacto em linguagem, especialmente a disponibilidade de livros na biblioteca escolar, sendo o umbral de mais de 1000 livros. A correspondente pesquisa qualitativa de escolas com resultados expressivos em sete países, realizada pelo Laboratório Latino-Americano para Avaliação da Qualidade da Edu- cação (MELLA et al., 2002) esclareceu que os estabelecimentos estudados não possuem grande quantidade de material didático, mas usavam o que tinham eficientemente. Segundo o SAEB, o livro didático em especial tem alcançado impacto digno de nota sobre o aproveitamento dos alunos (HARBISON; HANUSHEK, 1992). Pesquisa de Waiselfisz (2000d), com dados do SAEB-97 do Nordeste, revelou que os equipamentos e a infra-estrutura pedagógica da escola incidiam de forma positiva e significativa no aproveitamento, especialmente na oitava série.

\section{Tamanho da escola e da turma}

O tamanho da escola e da turma não assumem nas pesquisas a importância que têm no senso comum. Os resultados de uma escola ou turma menor não são necessariamente melhores. No entanto, se consideramos que o clima escolar, a pessoalidade do tratamento, a afetividade e a ausência ou poucos episódios de violências são características de escolas de sucesso (COHN; ROSSMILLER, 1987; SCHEERENS; BOSKER, 1997; SCHEERENS, 2000; CASASSUS, 2002; MELLA et al., 2002), os estabelecimentos maiores não são os mais recomendados. Com efeito, Harling-Hammond (1997) constatou que escolas pequenas, de 300 a 500 alunos, alcançam aproveitamento mais alto, maior assiduidade, menor evasão e menos indisciplina, considerando, assim, o tamanho da escola como variável importante. Também em relação aos EUA, o aproveitamento é maior em escolas de 600 a 900 alunos e que é mais eqüitativamente distribuído nestas escolas menores. Verifica-se também a tendência de as escolas maiores apresentarem maior número de casos de violências (DEBARBIEUX, 2002; DEBARBIEUX; BLAYA, 2002), sendo mesmo consideradas criminógenas. 
Por sua vez, a ampla resenha de Riordan (2004) deixa claro que, indisputavelmente, a escola primária deve ser pequena, havendo discussão quanto à secundária. Há também fortes evidências de que, em escolas secundárias menores, os alunos estão mais satisfeitos, são mais responsáveis e participativos e alcançam maior aproveitamento. Nas unidades escolares menores é mais fácil fazer face às culturas da juventude e ao comportamento desviante, tornar alunos e professores mais responsáveis, assim como reduzir a burocratização, os altos custos de coordenação e problemas de informação. Entretanto, parece que não se sabe precisamente como funciona o efeito desta variável, embora uma pesquisa tenha concluído que o tamanho influencia o rendimento discente direta e indiretamente por meio das atitudes dos professores em relação aos seus alunos, no sentido de maior responsabilidade coletiva. Ainda assim, parte importante do efeito direto do tamanho da escola sobre o aproveitamento permanece inexplicada.

Por sua vez, o tamanho da turma é alvo de controvérsias. Na América Latina as pesquisas não encontram relação com o rendimento ou produzem evidências pouco claras (CASTRO et al., 1984; COSTA, 1990). Casassus (2002) verificou que tanto turmas muito pequenas, como maiores de 25 alunos no ensino primário, apresentavam menor rendimento. Porém, segundo simulações, é alto o custo para aumentar em cinco pontos os escores de uma turma de 35 alunos. Na França, Barrère e Sembel (2002) afirmam que não parece haver relação entre as duas variáveis, tamanho da turma e aproveitamento. As resenhas internacionais encontram resultados divididos. Contudo, uma meta-análise de pesquisas verificou que os efeitos sobre o rendimento são mínimos em turmas de 20 a 40 alunos, mas as melhoras relevantes só aparecem em turmas de 15 alunos ou menos. Outra meta-análise encontrou resultados mais positivos para reduções da ordem de 27 a 16 alunos. Já um estudo comparativo interpaíses (Terceiro Estudo Internacional sobre Aproveitamento em Matemática e Ciências - TIMSS) não encontrou provas do benefício de turmas menores (RIORDAN, 2004). Mesmo para países desenvolvidos, os custos correspondentes podem ser impraticáveis, porém eles serão pequenos no caso da redução do tamanho das escolas, ainda mais com as convergências encontradas na situação atual do conhecimento sobre o tema.

No caso do Nordeste brasileiro, trabaIhando com dados do SAEB-97, Waiselfisz (2000a, 2000b) verificou que as escolas maiores eram as que apresentavam mais facilidades e serviços educacionais. Além disso, estes eram os estabelecimentos que recebiam os alunos de status socioeconômico - SSE, mais alto. Como o aproveitamento discente estava relacionado a tais facilidades e serviços, as escolas maiores eram as que apresentavam maior proficiência, mesmo controlando o SSE dos alunos. A nosso ver, esta constatação reflete a elevada variabilidade de recursos educacionais, típica dos países em desenvolvimento, ocultando outros fatores e efeitos que a literatura verifica em países desenvolvidos.

Quanto ao tamanho da turma, Waiselfisz (2000c, 2000d) confirmou em linhas gerais a literatura internacional: não foram encontradas evidências de que, quanto menor a turma, maior o seu aproveitamento. Ao contrário, até certo ponto, em torno 
de 40 ou 45 alunos, dependendo de determinadas circunstâncias, quanto maior a turma, maior o aproveitamento, mesmo desagregando os dados pela rede escolar e pela localização do estabelecimento.

\section{Tempo letivo}

A duração do tempo letivo e a sua extensão por meio dos deveres de casa apresentam alta incidência de relações positivas e significativas com o rendimento nas resenhas e pesquisas internacionais (SCHIEFELBEIN; SIMMONS, 1980; CASTRO et al., 1984; ROCHA, 1984; FULLER, 1987; COHN; ROSSMILLER, 1987). A jornada completa foi assinalada como fator de sucesso numa das avaliações do P-900 no Chile, ao passo que o tempo letivo em geral, no caso do Brasil, tem sido também destacado pelas pesquisas (BRANDÃO; BAETA; ROCHA, 1983; ARMITAGE et al., 1986; COSTA, 1990). Por outro lado, meta-análises de pesquisas norte-americanas sobre a aprendizagem nas férias escolares mostram que ocorrem perdas equivalentes, em média, a um mês de estudo por série. Entretanto, tais perdas são socialmente assimétricas: ao passo que os alunos socialmente privilegiados têm oportunidades educacionais informais, durante as férias de verão, para evitar o recuo dos seus conhecimentos, os alunos menos privilegiados e os de famílias monoparentais vão acumulando déficits de aprendizagem ano a ano e gerando um hiato em relação aos seus colegas mais favorecidos (RIORDAN, 2004).

Crahay (2002) também resenha uma série de pesquisas efetuadas em vários países, que corroboram de modo geral a associação entre tempo letivo e rendimento. Não contente, porém, com esta conexão geral, refina a análise dos trabalhos de modo a captar a complexidade dos processos envolvidos. Cabe recordar aqui a suposição simplificadora da escola como "caixa preta", onde, injetados os insumos, se obteriam determinados resultados. Esta relação, aparentemente linear, é intermediada por outras variáveis, como o tempo atribuído ao ensino pelos professores, o tempo de envolvimento do aluno na aprendizagem, o tempo de investimento dos alunos nas tarefas escolares, o tempo ativo de aprendizagem e o tempo consagrado à tarefa. Além destes, são analisadas as relações entre o conteúdo ensinado, o tempo atribuído e o tempo investido na aprendizagem. Alcançar o nível ótimo nas relações entre estas variáveis implica formas mais eficazes de organização do ensino e aquelas formas que o docente utiliza para suscitar relacionamentos, generalizações e debates sobre os novos conhecimentos apresentados. Podem ser acrescentadas também as diferentes formas de relacionamento entre professores e alunos, considerando a idade, a composição e os interesses das turmas, inclusive os limites interpostos ao ensino pelas culturas juvenis, que afetam a ordem e o interesse na sala de aula, conforme analisamos antes. Desta forma, como conclui Crahay (2002), se poderia aumentar infinitamente o tempo de ensino sem afetar o empenho dos alunos, - que retira qualquer idéia ilusória de uma relação automática entre tempo letivo e rendimento, por mais que o corpo de investigações seja favorável.

Quanto ao dever de casa, a relação também não parece ser automática. A pesquisa qualitativa sobre escolas bem sucedidas na América Latina revelou que estes trabalhos nem sempre apareciam entre as suas estratégias. Ao contrário, elas desenvolviam atividades tão intensas na sala de aula que as crianças continuavam o processo fora, mas não como deveres (MELLA et al., 2002). 


\section{Os professores}

Os docentes são usualmente recompensados em suas carreiras com base na escolaridade e no tempo de serviço, em gradação crescente. Entretanto, as resenhas das pesquisas mostram que estas são variáveis com impacto controvertido sobre o rendimento do aluno. Gênero, formação pedagógica, formação continuada e salário com muita freqüência não têm impacto significante (SCHIEFELBEIN; SIMMONS, 1980; FULLER, 1987; BARRÈRE; SEMBEL, 2002; WOESSMAN, 2002). Em certos casos o prolongamento da escolaridade se revelou menos apropriado para as séries iniciais (CASTRO et al., 1984). O tempo de experiência, em vez de ter um impacto crescente, parece percorrer uma linha ascendente e depois declinante (BARRÈRE; SEMBEL, 2002). A este propósito Lourenço Filho (1960) já constatara que o professor, para alcançar um patamar de rendimento satisfatório, precisava de cinco anos de experiência, entrando em declínio, naquela época, após 20 anos de atividade docente. Outra constatação importante é a prática comum no Brasil e outros países de atribuir as turmas mais difíceis aos professores menos experientes (BRANDÃO; BAETA; ROCHA, 1983). Esta é uma das dimensões da regressividade da escolarização, que desfavorece os alunos de mais baixo SSE, que mais necessitam de uma escola de qualidade. Uma pesquisa internacional, o TIMSS, constatou que, nos países e escolas em que os sindicatos de professores tinham maior influência sobre o currículo, o rendimento era menor. Quando os professores agem coletivamente, constituem um poderoso grupo político de interesse, cujas negociações favoreceriam antes o professor mediano que a diferenciação por mérito. A participação sindical também levaria ao incremento dos recursos escolares, mas estas duas variáveis são acompanhadas da diminuição do rendimento discente (WOESSMAN, 2004).

O PISA 2000 (OECD; UNESCO, 2003), por seu lado, encontrou efeitos destacados da disponibilidade de professores especialistas, fatores que afetam o clima escolar, o moral dos professores e seus compromissos e as relações professor-aluno. No caso da América Latina, a experiência docente entre 10 e 20 anos favoreceu o rendimento discente, assim como os salários, o vínculo contratual permanente e a formação póssecundária ou pós-média na docência das séries mais avançadas. Na quarta série do ensino primário os professores normalistas alcançaram melhores níveis de aproveitamento do que aqueles com a formação superior (CASTRO et al., 1984). Casassus (2002), mais recentemente, identificou fortes impactos da formação pós-média e da satisfação com o salário (não o salário em si, que daria origem a uma relação direta) ${ }^{2}$. Foram negativamente associados ao rendimento dos alunos: professores que trabalham em outros empregos além do magistério, falta de autonomia docente e alunos cujos mestres pensam que o seu êxito ou fracasso depende das condições familiares. Ao contrário, tenderam a associar-se baixas notas e a opinião dos professores de que elas não se devem às suas habilidades docentes, ou seja, uma atitude fatalista, que culpa as condições socioeconômicas do aluno.

${ }^{2}$ Cf. FARRELL, 1993. 
Quanto ao dimensionamento dos efeitos diretos do professor, Castro e outros (1984) verificaram que a variância do rendimento atribuído às variáveis do professor foi de $19 \%$ a $32 \%$ e de 5 a $13 \%$ de país para país, sendo maior o impacto nas séries iniciais. Estas proporções, em muitos casos relativamente reduzidas, expressam o impacto das variáveis "ortodoxas" utilizadas (escolaridade, experiência, salário etc.). As pesquisas qualitativas abrem novos horizontes ao captar outras faces do processo educativo e redimensionar a influência do professor. Assim, ao tratarem do efeito professor, Barrère e Sembel (2002) enfatizam, na experiência francesa, os desastres relacionais; as arbitragens complexas na avaliação, em que intervêm representações da profissão e dos alunos, inclusive estereótipos desfavoráveis relativos aos de baixo SSE; o aumento subjetivo da severidade nos níveis mais avançados (do collège para - liceu, isto é, do ensino secundário inferior para o superior), onde as notas atribuídas são menores, em que pese o aumento do investimento dos alunos no trabalho escolar, e a maior indulgência nos estabelecimentos de meio popular, sugerindo um comportamento paternalista, não desconhecido no Brasil (PEREIRA, 1969).

Ainda no caso da França, Meuret (2000), estudando dados quantitativos e qualitativos sobre o efeito estabelecimento no ensino secundário e, portanto, em grande parte o efeito professor, concluiu que: 1) quanto mais eficazes as escolas, menos eram seletivas (se sabiam ensinar, não dependiam tanto da escolha dos melhores alunos para nelas se matricularem); 2) a eficácia se traduziu na melhoria do aproveitamento dos alunos "fracos", na proporção de duas vezes mais importância que para a média dos discentes; 3) métodos pedagógicos, estilos de ensino, diplomas e formação do corpo docente não fizeram diferença, do que se pode inferir que havia tanto bons quanto maus professores utilizando os mesmos métodos e estilos; 4) os professores mais severos na avaliação eram justamente os menos eficazes; 5) os docentes menos eficazes eram os que tinham conceito negativo sobre os seus alunos e não se sentiam à vontade no relacionamento com eles; 6) os docentes eficazes tinham visão realista e diferenciada dos seus alunos, declarando que deviam adaptar a estes os seus modos de ensino quando o nível era baixo, sem, todavia, reduzir as suas exigências (isto é, mantinham os objetivos, porém, diversificavam as estratégias). Além disso, o seu ensino era estruturado, com avaliações freqüentes, realizadas com justiça e consideração, sem humilhar os alunos; 7) nas classes dos professores eficazes estudavase grande parte do programa, com menor perda de tempo, inclusive por haver menos indisciplina; 8) a unidade de objetivos, métodos e práticas entre docentes não afetou a eficácia na França, ao contrário dos EUA. Portanto, os atributos dos professores eficazes são precisamente aqueles que escapam aos critérios burocráticos de recompensas em suas carreiras, de tal modo que continua de pé a questão de como selecionar, gratificar e promover os melhores, em detrimento dos piores. Este caminho, segundo várias investigações, não passa pela abordagem pedagógica ou metodológica, isto é, existem bons e maus professores que esposam as diferentes abordagens. 
Na América Latina, Mella e outros (2002) detectaram muitos aspectos influentes sobre o clima escolar. $O$ respeito às opiniões do corpo docente, em estruturas escolares não autoritárias; o compromisso; a vocação; a liderança pessoal; o apoio individual ao aluno; o compartilhamento das responsabilidades; demonstrações de afeto e tratamento pessoal; baixo grau de flutuação de professores (ou seja, manutenção do mesmo professor durante todo o período letivo) e as altas expectativas em relação aos alunos foram elementos-chave das escolas bem sucedidas. Uma avaliação do programa chileno P-900 também indicou a relevância da baixa flutuação de profissionais, do seu envolvimento, qualificação e liderança (CARLSSON, 2000).

O quadro 1 sintetiza de modo muito sumário o impacto destas diferenças entre escolas. A cautela, porém, deve guiar a leitura de quaisquer constatações da literatura. Esta com freqüência verifica o impacto de uma variável sobre outra, podendo controlar os efeitos de terceiras. Além disso, os impactos podem não se situar acima do nível estatisticamente significativo estabelecido em determinadas situações, mas, sim, em outras. Deste modo, por exemplo, o gênero dos professores não apareceu com efeitos significativos para a aprendizagem, mas um corpo docente eminentemente masculino, em certas culturas, pode inibir a freqüên- cia e o rendimento das meninas. Por outro lado, como vimos, o magistério feminino pode causar dificuldades ao desempenho dos rapazes. O aumento das despesas por aluno, quando o limiar é muito baixo, pode ter notável impacto sobre a melhoria da aprendizagem, porque supre carências básicas, que fazem muita diferença. Assim, as constatações das pesquisas devem ser sempre tratadas com cautela, sem simplificações e generalizações indiscriminadas e, sobretudo, sem dar origem a pretensos dogmas.

\section{O clima escolar}

As escolas bem sucedidas - e as diferenças entre as mais e menos bem sucedidas - fogem como a água por entre os dedos dos pesquisadores, sobretudo dos mais ortodoxos. Por isso mesmo, as constatações se baseiam em grande parte na análise qualitativa, que destaca o clima escolar e o clima da sala de aula. As conclusões convergem para uma atmosfera de encorajamento, altas exigências, tratamento pessoal, liderança - do diretor, que tem papel estratégico, e do corpo docente -, cordialidade, disciplina, relações mais próximas com a família e os alunos e, parcialmente em conseqüência disto, apoio dos pais $^{3}$. O resultado de um exaustivo levantamento das pesquisas com variadas metodologias, foi sumariado, no que concerne às diferenças inter-escolares, por Scheerens e Bosker (1997) e Scheerens (2000), conforme o quadro 2.

${ }^{3}$ Cf., p. ex., COHN; ROSSMMILLER, 1987; DARLING-HAMMOND, 1997; CARLSSON, 2000; OECD; UNESCO, 2003; ABRAMOVAY et al., 2003. 


\section{Quadro 1}

\section{Os Impactos das Diferenças entre Escolas}

\section{FATORES INFORMAÇÕES DA LITERATURA}

\begin{tabular}{l|l} 
Despesa por aluno & Sem relação automática. Passa pela intermediação dos
\end{tabular} processos escolares.

\begin{tabular}{l|l} 
Instalações e recursos & Impacto pequeno a moderado. Recursos (biblioteca, livros
\end{tabular} didáticos etc.) têm efeitos mais intensos que as instalações.

Tamanho da escola

Vantagens para escolas menores, sobretudo na educação primária

Tamanho da turma

Efeitos controversos. Meta-análise: efeitos mínimos em turmas de 20 a 40 alunos. Melhoras relevantes em turmas de 15 alunos ou menos. Implicação de altos custos.

Tempo letivo

Relações positivas e significativas em geral.

Efeito socialmente regressivo do hiato das férias de verão. Intermediação de variáveis como tempo de envolvimento do aluno na aprendizagem, tempo letivo de aprendizagem e tempo consagrado à tarefa.

Relações entre o conteúdo ensinado, o tempo atribuído e o tempo investido na aprendizagem, isto é, importa o que é feito com o tempo letivo.

Dever de casa Prolonga tempo letivo. Relação positiva, mas não automática.

\begin{tabular}{|l|l|}
\hline Professores: & \\
\hline Gênero & Sem efeitos significativos. \\
\hline Formação pedagógica & Sem efeitos significativos. \\
\hline Formação continuada & Sem efeitos significativos. \\
\hline Salário & Sem efeitos significativos \\
\hline Experiência & Parece obedecera uma curva ascendente e depois descendente \\
\hline $\begin{array}{l}\text { Constituição de poderoso } \\
\text { grupo de interesse }\end{array}$ & Indícios de efeitos negativos. \\
\hline Satisfação com o salário & Efeitos positivos e significativos. \\
\hline Formação pós-média & Efeitos positivos e significativos. \\
\hline $\begin{array}{l}\text { Aspectos qualitativos, como } \\
\text { expectativas, aspectos } \\
\text { emocionais, estereótipos }\end{array}$ & Efeitos significativos \\
\hline Métodos pedagógicos & Indiferentes. \\
\hline
\end{tabular}




\section{Quadro 2}

\section{Componentes de Fatores de Efetividade ao Nível da Escola}

\begin{tabular}{|c|c|}
\hline FATORES & COMPONENTES \\
\hline Liderança educacional & $\begin{array}{l}\text { Capacidade geral de liderança } \\
\text { Líderes escolares como provedores de informações } \\
\text { Líderes como orquestradores de processos decisórios par- } \\
\text { ticipativos } \\
\text { Líder escolar como coordenador } \\
\text { Líder como supervisor dos processos de sala de aula } \\
\text { Liderança educacional e administrativa } \\
\text { Líder como conselheiro e supervisor dos professores em } \\
\text { sala de aula } \\
\text { Líder como iniciador e facilitador da profissionalização da } \\
\text { equipe }\end{array}$ \\
\hline $\begin{array}{l}\text { Consenso e coesão } \\
\text { da equipe escolar }\end{array}$ & $\begin{array}{l}\text { Tipo e freqüência de reuniões e consultas } \\
\text { Conteúdos da cooperação } \\
\text { Satisfação em face da cooperação } \\
\text { Importância atribuída à cooperação } \\
\text { Indicadores da cooperação bem sucedida }\end{array}$ \\
\hline Clima da escola & $\begin{array}{l}\text { Atmosfera de ordem } \\
\text { Importância atribuída a um clima de ordem } \\
\text { Normas e regulamentos } \\
\text { Sanções e recompensas } \\
\text { Absenteísmo e evasão (baixos ou nulos) } \\
\text { Boa conduta dos alunos } \\
\text { Satisfação com um clima de ordem }\end{array}$ \\
\hline Potencial de avaliação & $\begin{array}{l}\text { Ênfase à avaliação } \\
\text { Monitoramento do progresso dos alunos } \\
\text { Uso (efetivo) dos sistemas de monitoramento dos alunos } \\
\text { Avaliação do processo escolar } \\
\text { Uso dos resultados da avaliação } \\
\text { Manutenção de registros do desempenho discente } \\
\text { Satisfação com as atividades de avaliação }\end{array}$ \\
\hline Envolvimento dos pais & $\begin{array}{l}\text { Ênfase ao envolvimento dos pais na vida escolar } \\
\text { Contatos com os pais (constantes) } \\
\text { Satisfação com o envolvimento dos pais }\end{array}$ \\
\hline
\end{tabular}

Fonte: Fundamentado em Scheerens e Bosker (1997); Scheerens (2000) 
Uma ambiência democrática (não populista), certo grau de consenso entre os professores, ordem, forte interesse pelos alunos, foco nas atividades educacionais e constante acompanhamento e avaliação são ressaltados como atributos de uma escola efetiva. Diante destes resultados do corpo de investigação, é interessante lembrar em que medida a formação inicial e continuada do magistério desenvolve tais características e em que medida a carreira as premia ou sanciona.

Esta interessante convergência de resultados se reflete em pesquisas sobre a América Latina. No modelo de Casassus (2002), a mais relevante variável explicativa do aproveitamento discente foi o clima favorável à aprendizagem, definido como situações em que os alunos se davam bem com os colegas, não havia brigas, o clima escolar era descrito como harmonioso e não havia interrupções das aulas. A pesquisa qualitativa que escrutinou escolas bem sucedidas a partir do mesmo estudo (MELLA et al., 2002) acentuou o papel destacado dos alunos e dos pais como atores significantes, do trabalho em equipe dos professores e diretores, do clima organizacional aberto à mudança, do espírito não autoritário, da afetividade e confiança, do respeito mútuo e da relevância da brincadeira como meio de fazer da escola um lugar prazeroso. Os estabelecimentos educacionais selecionados podiam ser pequenos ou grandes, urbanos ou rurais, particulares ou públicos, leigos ou religiosos, mas se caracterizavam pelas altas expectativas dos professores quanto à aprovação dos alunos, pela ação inovadora destes, pela não escolha de uma perspectiva pedagógica particular (que, quando selecionada, não raro é considerada miraculosa - comentá- rio nosso) e pela tentativa de não criar hierarquias e não classificar os estudantes, colocando em xeque as formas tradicionais de avaliação. É interessante observar que tais escolas também dedicavam grande atenção às atividades extra-curriculares. A família tinha uma atitude participativa na gestão da escola, não se limitando a comparecer quando convidada. Uma questão interessante é que o conjunto de valores, motivações, capacidades e compromissos levavam diretores e professores a agir de modo a estruturar estes locais agradáveis e efetivos de ensino-aprendizagem.

Quanto à relação entre o clima escolar e a qualidade da educação, não deve passar despercebida uma pesquisa com alunos, pais e professores de dois Estados brasileiros. A escola de qualidade foi considerada como aquela em que os alunos gostam de aprender e que trata bem os seus alunos, não importando a sua cor ou origem social. Para os discentes o prazer de ir à escola estava ligado ao gosto de encontrar amigos e colegas, ao desejo de aprender e aos professores que ensinavam bem (CAMPOS, 2002). É interessante observar que os juízos foram, de modo geral, bastante simples, mas significativos. A qualidade não foi traduzida por atributos intelectuais sofisticados, mas, em grande parte, pelo gosto de ir à escola. Isto reflete provavelmente o fato de que a média de anos escolaridade dos pais é reduzida, como a média do país, e, em muitos casos, é inferior à dos próprios filhos.

\section{A gestão escolar}

A autonomia escolar é um tema recorrente quando se trata do sucesso das escolas e dos alunos. Embora não possa fazer inferências causais, o PISA 2000 (OECD; UNESCO, 2003) verificou que, em média, os resultados de lei- 
tura acompanharam a autonomia escolar em termos de alocações orçamentárias internas, escolha de livros didáticos, estabelecimento de normas disciplinares e determinação dos cursos oferecidos. Já uma análise do TIMSS encontrou resultados mistos. Foram preditores favoráveis ao aproveitamento discente a capacidade de decidir sobre a compra de materiais, contratação e remuneração de professores e escolha de métodos didáticos. $\bigcirc$ mesmo não ocorreu com outras variáveis, que tiveram efeito depressivo sobre o rendimento: capacidade de as escolas decidirem sobre o currículo, aprovação de livros didáticos e determinação do orçamento da escola (WOESSMAN, 2004). Na América Latina, por seu turno, Casassus (2002) construiu um índice de autonomia (constituído das seguintes variáveis: liberdade de nomeação e demissão de pessoal; distribuição do orçamento; seleção de livros didáticos; normas de admissão, suspensão e expulsão de alunos; critérios para aprovação dos alunos; formulação e modificação de normas disciplinares; estabelecimento de prioridades pedagógicas e atividades extracurriculares). Este índice de autonomia apresentou correlação positiva com o rendimento discente, junto com a liderança do diretor. A pesquisa qualitativa do mesmo Laboratório Latino-Americano de Avaliação da Qualidade da Educação (MELLA et al., 2002) apontou para o compartiIhamento de responsabilidades pela equipe escolar, não concentração da liderança na figura do diretor, normas explícitas, estabilidade no suprimento de recursos, eficiente uso do espaço, do tempo e dos materiais e funcionamento autônomo. Portanto, a autonomia tende a associar-se a resultados positivos, embora certas decisões possam ser melhor atribuídas aos níveis centrais do sistema educacional. Em outros termos, a autonomia é solução para amplo espectro de problemas, mas não é uma panacéia.

\section{Os efeitos dos colegas}

$O$ protagonismo dos alunos tem crescente importância para os objetivos da escola serem ou não atingidos. A pesquisa pioneira sobre o tema foi a de Coleman (1960, 1963), em dez escolas secundárias americanas, de vários tamanhos, com diferenças no seu sistema de status e localizadas em vários tipos de comunidades. Após a Segunda Guerra Mundial, o trabalho dos pais fora de casa, a saída dos adolescentes do mercado de trabalho, a extensão da escolaridade e a escola de jornada completa, levaram à diminuição da convivência entre as gerações e ao apoio dos adolescentes nos seus próprios colegas. Encontrando casas vazias no regresso da escola, desenvolveram seus próprios grupos, com uma cultura própria. Seus contatos com o mundo dos adultos passaram a ser mediados (e também distorcidos) sobretudo pelos meios de comunicação de massa. Seus heróis se tornaram os do cinema e da televisão. Suas aspirações ocupacionais com freqüência se converteram em ser modelo, estrela do cinema, atleta famoso ou piloto de jato. Como resultado, eles desenvolveram padrões específicos de comportamento e vocabulário, tornando-se um grupo de consumo de elevado interesse para o mercado. Mais importante, contudo, é o valor do grupo de adolescentes. Enquanto os pais e professores possuíam o controle de recompensas sociais para motivar os adolescentes, agora eles passaram a receber muito mais retribuições dos seus próprios companheiros, não materiais, mas um sistema de recompensas e punições refletido na distribuição de status dentro do grupo.

As conseqüências educacionais são ponderáveis. Erra a escola que focaliza os indivíduos, não os grupos, uma vez que estes podem conduzir as energias para objetivos não acadêmicos. No sistema de status dos 
adolescentes é mais importante ser um atleta ou uma garota atraente que obter boas notas. A pouca importância relativa do aproveitamento escolar sugere que aqueles que são vistos como "intelectuais" podem não ser exatamente os que possuem mais inteligência, mas apenas aqueles que estão dispostos a trabalhar arduamente numa atividade de baixo nível de recompensas.

Estas condições são propícias ao fortalecimento das sociedades de adolescentes e jovens (e também de crianças), com o seu dinamismo próprio e uma capacidade de interlocução e barganha muito mais intensa em relação à escola e aos mundos dos adultos. Conforme Dubet e Martuccelli (1996), a socialização pode ser caracterizada pelo distanciamento do indivíduo em relação às lógicas sociais que orientam a sua ação. Cada situação escolar é caracterizada por uma combinação de três lógicas de ação: de integração, pela qual o aluno se define em função da sua participação na escola e, sobretudo, na cultura juvenil; estratégica, pela qual o aluno age do melhor modo segundo os seus interesses escolares e de subjetivação ou de construção do próprio sujeito, à distância dos outros dois registros de ação. Deste modo, é possível ir muito mais além do conceito de sociedade adolescente, dos anos 60, e extrair implicações para a organização e o funcionamento da escola de massa.

Com razão Barrère e Sembel (2002) destacam que a ênfase da teoria de Dubet no papel da subjetividade do aluno na construção da sua experiência escolar foi negligenciada pela sociologia clássica. Esta não observou para onde se movimentavam as águas da pedagogia, que se deslocavam do aluno como objeto para centrar-se no aluno como sujeito, chegando à relação dialógica entre aquele que predominantemente ensina e aquele que predominantemente aprende, conforme uma frase de Durmeval Trigueiro Mendes. Tais mudanças, facilmente reconhecidas dos pontos de vista filosófico e metodológico, têm sido acompanhadas recentemente, no campo das relações econômicas, pela visão do aluno como cliente de serviços educacionais.

Por isso, o tecido de relações e grupos sociais da escola ganhou uma trama ainda mais intrincada. Embora as relações de cooperação continuem necessariamente a existir dentro de cada grupo e entre os grupos constitutivos da escola, o pêndulo parece inclinar-se para os processos de conflito. A escola é comparável a uma arena competitivo-conflitual, onde se encontram culturas de pelo menos duas gerações. No seu espaço social, segundo a já referida sociologia da experiência, proposta por Dubet (1996), os alunos se constróem como sujeitos, mantendo relações geralmente contraditórias com a cultura escolar e diferentes grupos de colegas. É importante ter em mente a diversidade de valores, normas, padrões de comportamento e interesses (COLEMAN, 1963), em que avultam as suas origens sociais. Conforme Dubet e Martuccelli (1996), os alunos socialmente privilegiados, mais próximos da cultura escolar, se integram à cultura juvenil com desafios à escola mantidos dentro de certos limites. Enquanto isso, os alunos das classes populares, mais distantes da cultura escolar, são, por isso mesmo, marcados freqüentemente por experiências de fracasso, de modo que a sua integração aos colegas e às culturas juvenis se faz pela via da afirmação pessoal, com rebeldia aberta contra a escola. 
Nesta arena que se mantém unida de maneira mais ou menos precária em face da pluralidade de valores e modelos, se estabelecem contínuas negociações de consenso e compromisso, de tal modo que a autoridade e a motivação para o trabalho escolar devem ser reconstruídas dia a dia pelos professores (DUBET, 2002). O papel profissional destes já não lhes confere automaticamente autoridade, ao contrário, esta precisa ser negociada cotidianamente e legitimar-se a cada momento, dissociada, tanto quanto possível, do poder. À falta do apoio de valores e normas inequívocos, a autoridade docente, na tipologia de Weber (1968), afasta-se cada vez mais dos tipos ideais tradicional e burocrático: o professor depende cada vez mais do seu próprio carisma. Caminhando sobre a lâmina da faca, o docente precisa evitar tanto o excesso de poder, considerado como "sadismo", quanto a sua falta, encarada como "fraqueza" ante os alunos. Carentes de princípios centrais e homogêneos, os educadores precisam proceder a arranjos locais entre normas contraditórias (por exemplo, princípios do mérito e da igualdade educacionais) e negociar a disciplina em função dos indivíduos, grupos e casos (DU$B E T, 2002)$. Não é, pois, de admirar que os docentes, muitas vezes em função de uma perspectiva paradisíaca ou saudosista do passado, se sintam desvalorizados, sofram de estresse e parte deles padeça do chamado burn out (no sentido de esgotamento das suas capacidades).

Este novo protagonismo discente, exercido por adolescentes e jovens, indica que o grupo de colegas tem influência na aprendizagem e no processo educativo em geral, influência esta que varia conforme as suas origens sociais. Chegamos, portanto, ao coração da cebola. Neste sentido, diversas pesquisas têm concluído, embora com contestações, que o SSE dos alunos tem um papel relevante ao modelar as suas aspirações, ou seja, quanto mais alto o SSE, maiores os estímulos para ir adiante na escala educacional e vice-versa. Evidências interessantes se agregaram, esclarecendo que o impacto do contexto da escola, com a respectiva composição social do corpo discente, é exercido em grande parte pela via do clima escolar. Em outras palavras, as interações dos alunos com colegas mais privilegiados levaria a melhores resultados no estudo e a aspirações mais altas, o oposto sendo verdadeiro. Mais ainda, pesquisas têm revelado que o contexto socioeconômico escolar é o mais importante aspecto intra-escolar. Este contexto é explicado pelo clima da escola, ou seja, não é o contexto socioeconômico em si que gera resultados acadêmicos positivos, mas existe uma espécie de correia transportadora, que é o clima da escola. Desta forma, o clima positivo no estabelecimento de ensino, associado ao SSE dos alunos, conduz a bons resultados acadêmicos (RIORDAN, 2004).

\section{Estas conclusões permitem levar a duas linhas de indagação:}

1) Se o alunado tem maiores afinidades ou menor hiato em face da cultura escolar e se o SSE incentiva um nível aspiracional mais alto, a composição do corpo discente é importante. Escolas segregadas levariam numerosos grupos ao afastamento da escola e ao insucesso acadêmico. Assim, em vez da homogeneidade, a heterogeneidade entre as escolas e dentro de cada escola teria um efeito positivo, ainda que não fosse poderoso, mas, de qualquer forma, não negligenciável. Deste modo, a escolha da escola e o agrupamento de alunos por turma podem 
ter sérias implicações para o sucesso e a eqüidade, como veremos depois.

2) Se o clima escolar tem a relevância pedagógica que as pesquisas revelaram, consoante o item anterior, e se ele é influenciado pelo SSE dos alunos, estaríamos diante de um processo em parte modelado pela escola. Assim, a ação escolar em favor de maior eqüidade teria o clima como uma área em que interagem o background socioeconômico do alunado e condições do próprio estabelecimento, examinadas antes. Sendo um "território comum" a diversas influências, existe uma faixa em que os educadores podem atuar e gerar resultados positivos.

Este terreno, contudo, contém um labirinto mais intrincado do que parece e requer maior aprofundamento. De fato, há várias interpretações alternativas dos efeitos dos colegas. Uma delas sugere que os seus efeitos resultam do fato de os estudantes internalizarem as normas da escola para orientar a sua aprendizagem e o seu comportamento. Outra sugere que os seus efeitos se devem ao uso da escola como grupo de referência para fazer comparações sobre o seu desempenho e desenvolver autopercepções acadêmicas. Uma terceira alternativa, ainda, sugere que os efeitos se devem à modificação das práticas da escola e dos professores para se adaptarem às características do corpo discente. Por fim, outros trabalhos propõem que os impactos das estruturas educacionais são mediados por sucessivos níveis da organização social, mais uma vez segundo uma estrutura comparável à da cebola, em que, a cada casca que se abre, se encontra outra. Assim, é possível chegar ao que alguns consideram o locus dos efeitos dos colegas, os pequenos grupos discentes, como díades, cliques, grupos de estudo, lúdicos, associativos etc., que são influenciados pela composição dos grupos maiores, como as tur$\mathrm{mas}^{4}$. Estes comporiam o coração da cebola, com as suas camadas mais internas, tendo em vista a importância das culturas juvenis. Utilizando uma linguagem metafórica, que constitui aproximação tosca da realidade, depois de abertas as camadas da escola, da turma e do professor, teríamos esta parte central, cujas últimas camadas a escola deve atravessar para chegar ao aluno. As culturas da juventude constituem como que uma cápsula cujo ingresso nela precisa ser cuidadosamente negociado. Ao contrário da verdadeira cebola, esta parte central e mais íntima não é a mais tenra e, sim, a mais dura e difícil de ser atingida. Porém, se estas camadas estão no âmago da cebola, na verdade elas representam as conexões dos alunos com o mundo exterior, de tal modo que a sua participação na escola, como membros de grupos, é condicional. Conforme a expressão de Estêvão (2004), o aluno não é cidadão pleno da sua escola.

No entanto, segundo a perspectiva de Wilkinson e outros (2002), os professores não parecem perceber a complexidade das estruturas informais da escola. Do ponto de vista do ensino (não da aprendizagem), os efeitos dos colegas, tanto ao nível da escola quanto da turma, afetam apenas a probabilidade de diversas alternativas de ensino-aprendizagem ocorrerem e, ainda assim, tais efeitos seriam indiretos. Isto ocorre em grande parte porque os professores parecem não alterar as suas práticas quando a composição das turmas e grupos é

${ }^{4}$ Cf. WILKINSON et al., 2002. 
alterada e, também, porque o poder dos efeitos dos colegas raramente é percebido. Deste modo, não adiantaria agrupar os alunos de diferentes formas, promover a integração racial de escolas, diminuir o tamanho das turmas, criar estabelecimentos só para meninos ou meninas, pois a qualidade e a natureza do ensino não variam, no máximo os docentes adaptam o ritmo. Assim, o ensino não mudaria, apesar de mudarem condições relevantes de aprendizagem, sugerindo que o processo continua centrado no professor e não no aluno. Os impactos diretos da composição do corpo discente estão menos relacionados aos resultados da aprendizagem e mais ligados à eqüidade e aos efeitos das expectativas de professores, alunos, pais e gestores (HATTIE, 2002).

Um modelo alternativo sugere que os efeitos dos colegas sobre o aproveitamento parecem menores, em termos estatísticos, porque são intermediados por diferentes níveis ou camadas, segundo a estrutura da cebola, isto é, da escola, da turma e dos diversos grupos informais de colegas. Aumentando a complexidade, existe uma rede de relações recíprocas entre estudantes, professores e organização e gestão escolares. Ao nível do grupo de aprendizagem, a interação aluno-professor parece estabelecer culturas de grupo ou normas de comportamento que apóiam a aprendizagem de modos diversos. Nas turmas, diferentes formas de agrupamento podem construir diversas culturas de sala de aula que influenciam o que é ensinado (WILKINSON et al., 2002).

\section{A alocação da matrícula e a ges- tão do espaço}

Outro foco da pesquisa sobre a escola- rização como espelho e geradora de diferenças sociais é a alocação dos alunos às escolas nas redes públicas, distribuídas por espaços urbanos altamente estratificados em termos de renda dos residentes, valor venal dos imóveis etc. Um critério oficial amplamente adotado tem sido a matrícula segundo a área residencial, conforme o uso corrente em muitas redes brasileiras, a carta escolar na França e os critérios mais convencionais de muitos distritos escolares dos EUA. Um dos fundamentos para este critério básico é a economia dos custos de transporte, quer a cargo da família, quer do poder público. Quanto mais próximo o aluno da sua escola, menores são os custos de transporte e também de tempo. Com isso, a matrícula por área residencial tem implicações sociais e econômicas, inclusive imobiliárias: para ter acesso a boas escolas pode ser preciso residir numa área mais cara e, por outro lado, o fato de haver boas escolas pode elevar os preços das habitações.

As pesquisas já examinadas sobre o clima escolar, a influência dos colegas e as desigualdades de recursos entre as escolas mostram que os efeitos desta distribuição de recursos tende a ser regressiva, ou seja, reforçadora das diferenças sociais pré-existentes, conduzindo não raro à segregação escolar e à formação de "escolas guetos" e "escolas santuários" na mesma área. Havendo ou não vinculação entre residência e matrícula, existe o fenômeno das escolas "bem" e "mal amadas", com o afluxo de alunos em busca de melhor ensino, a formação de filas nas primeiras, a conseqüente adoção de critérios seletivos e, por outro lado, as tentativas de preenchimento pelo sistema da capacidade ociosa dos estabelecimentos menos desejados (GOMES; CASTRO, 2003). A própria carreira docente tende a premiar a remoção 
para as áreas urbanas mais valorizadas, ao passo que a complementação do financiamento público escolar, por meio de contribuições das famílias e da comunidade, tende a fazer os rios correrem para o mar, isto é, as áreas mais privilegiadas arrecadam mais e permitem maiores melhorias das escolas, ao passo que ocorre o inverso nas demais (MALDI; GOMES, 2003). Segundo o critério habitacional de distribuição de matrículas, uma das implicações é que a escolarização fica estreitamente vinculada à renda e aos atributos socioculturais dos alunos e das famílias valorizados para o êxito escolar.

Por motivos diferentes, entretanto, a alocação da matrícula segundo a residência tem levado pelo menos a duas posições: uma, já examinada antes, que é a da construção de um quase mercado educacional, estimulando a escolha dos pais e a competição mais ou menos livre das escolas. Isso inclui alternativas como o vale educação, as charter schools e as magnet schools nos EUA. Estas últimas são escolas com focos especiais de excelência (como artes, ciências etc.), a cuja matrícula os alunos se candidatam com menores restrições de residência. Uma das suas bases lógicas é que todos os alunos são capazes de aprender e que, para tanto, as diferenças devem ser contempladas. Como já vimos, o quase mercado não parece ser uma alternativa altamente efetiva para reduzir a desigualdade e a segregação.

A outra resposta é manter a própria limitação da escolha das escolas por meio da vinculação à área residencial. Crahay (2002) estabeleceu três hipóteses quanto à forma de reduzir as desigualdades sociais de sucesso escolar: 1) a abolição da repro- vação; 2) a supressão de áreas no princípio do ensino secundário, prolongando o tronco comum, e 3) a limitação da liberdade de escolha pela setorização. Ao testar as hipóteses com dados do estudo internacional sobre competências de leitura da IEA, aquele autor verificou que os países que se empenham em evitar a agregação dos alunos da mesma origem social e/ou com o mesmo nível de competência por intermédio destas três alternativas caracterizam-se por menores desigualdades que os outros. A parte da variância do aproveitamento discente em leitura imputável à escola é mais baixa que nos outros países e a proporção de alunos fracos é menos elevada.

Evidentemente esta alternativa é limitada. Em primeiro lugar, como o próprio Crahay (2002) observa, a setorização da matrícula depende de duas condições: 1) que a distribuição da população no território não seja demasiado marcada pelas diferenças sociais; 2) que a rede particular seja de pouca densidade para não interferir na organização do conjunto do sistema. Ora, os países igualitários detectados pelo teste de hipóteses são os nórdicos, onde a estratificação social é mais igualitária, remetendo, assim, de volta às matrizes das desigualdades sociais e às forças políticas que modelam as políticas públicas. Este círculo vicioso é o mesmo das frustrações em face das tentativas de dessegregação escolar nos EUA ou da não sustentação política de fórmulas de alocação de recursos que visam, numa pluralidade de casos, a reduzir desigualdades espaciais e sociais ${ }^{5}$. Como na história do ovo e da galinha, o rompimento do círculo vicioso depende de novas alternativas politicamente viáveis.

${ }^{5}$ Cf., p. ex., Elhav (1998) e Nakib e Herrington (1998). 


\section{Diferenças Dentro das Escolas}

Acompanhando a estrutura da cebola, após abrirmos a camada do efeito escola, temos as camadas da sala de aula e dos professores. Dentro de cada escola pode haver diferenças no processo de ensinoaprendizagem conforme, entre outros aspectos, a composição das turmas, a alocação dos professores e de recursos e, ainda, os processos educativos no âmbito de cada sala de aula.

Uma ampla resenha das pesquisas aponta para alguns fatores de aumento da efetividade ao nível das salas de aula. $\bigcirc$ clima e a organização do processo de ensino-aprendizagem têm papel relevante e as condições podem variar tanto de sala para sala, quanto em relação a grupos discentes e a alunos individualmente. Como os processos educativos são muito sensíveis às origens sociais dos alunos, pode haver diferenciações do tratamento segundo o status e, conseqüentemente, efeitos regressivos (dar menos a quem tem menos), em vez de efeitos progressivos (dar mais a quem tem menos).

Por outro lado, a meta-análise e a síntese das melhores evidências de investigações destacam três condições básicas de ensino, que têm maior impacto que os insumos e, pela sua simplicidade, estão ao alcance de qualquer país em desenvolvimento (SCHEERENS; BOSKER, 1997; SCHEERENS, 2000):

- Tempo dedicado às tarefas (extensão e aproveitamento);

- Cobertura dos conteúdos pelos instrumentos de avaliação;

- Abordagem estruturada: objetivos es- pecíficos, acompanhamento e retorno do desempenho dos alunos.

Ainda, as variáveis que emergem reiteradamente dos estudos parecem retiradas de qualquer livro sensato sobre didática (SCHEERENS; BOSKER, 1997; SCHEERENS, 2000, grifo nosso):

- Clareza: apresentação clara e adequada ao nível cognitivo dos alunos.

- Flexibilidade: variação do comportamento e assistência do professor, diversificação das atividades.

- Entusiasmo, refletido nos comportamentos verbais e não verbais do professor.

- Comportamento profissional: orientar os alunos a cumprirem as suas tarefas com profissionalismo.

- Crítica: crítica negativa em excesso tem efeito desfavorável sobre o aproveitamento.

- Atividade indireta: aceitação de idéias e sentimentos dos alunos e estímulo à atividade independente.

- Oferecer aos alunos oportunidade de aprender com materiais didáticos, orientados segundo os critérios de avaliação, de modo que o que é ensinado à turma seja devidamente avaliado.

- Comentários estimulantes: dirigir o pensamento dos alunos para as questões, sumariar discussões, indicar o começo e o fim de uma lição, enfatizar certos pontos do material de ensino.

- Diversificar o nível tanto das questões de avaliação como da interação cognitiva.

Quanto à América Latina, cumpre lembrar um estudo comparativo sobre as dife- 
renças de aproveitamento em matemática na terceira série em três países incluídos pela pesquisa do Laboratório Latino-Americano de Avaliação da Qualidade (CASASSUS, 2002): Brasil, Chile e Cuba. Os resultados do aproveitamento foram muito mais altos no último e equivalentes nos dois primeiros países. Embora no caso da investigação sobre matemática os alunos cubanos tivessem SSE mais alto, algumas das constatações mostram que nas escolas selecionadas de Cuba havia menos alunos por turma; mais ordem; menos interrupções; os alunos estavam mais envolvidos; faziam exercícios e resolviam mais problemas individualmente, com os professores circulando, e o nível de exigências cognitivas era mais alto (CARNOY; GOVE; MARSHALL, 2003). Evidentemente, esta não é uma receita de bolo, nem os resultados de uma pesquisa qualitativa podem ser indiscriminadamente generalizados, porém detectamos vários pontos de congruência com a literatura acima examinada.

Além destas características de tratamento, a literatura se preocupa com a hierarquização de status na sala de aula, já que as expectativas estão associadas às posições de status, com freqüência determinadas por fontes estruturais de desigualdade, como a etnia e a posição socioeconômica (RIORDAN, 2004). Esta hierarquia acaba levando à dominância de determinados grupos, de tal maneira que o professor precisa: 1) contrabalançar a composição dos grupos, reunindo alunos que tenham competências diferentes, que se equilibrem; 2) examinar criticamente as suas expectativas; 3 ) estimular sobretudo os alunos em desvantagem e utilizar o ensino cooperativo ${ }^{6}$.

\section{A formação de turmas}

Grande número de sistemas educacionais tende a formar turmas de acordo com o aproveitamento, optando pela homogeneidade, em vez da heterogeneidade. Esta prática fez correrem rios de tinta, com pesquisas evidenciando efeitos favoráveis e desfavoráveis. Considerando o panorama atual, delineado a partir das resenhas de centenas de pesquisas, temos as seguintes conclusões e ponderações:

- Segundo a meta-análise de centenas de estudos, o impacto da organização das turmas por aproveitamento existe, mas é diminuto, da ordem de 0,05 (quando ponderado pelo número de estudos é de -0,05). Por isso, o seu efeito está situado entre as intervenções educacionais de menor efeito, considerando que o impacto típico do total de intervenções educacionais é de 0,40 (HATTIE, 2002).

- Assim, de acordo com a vertente das pesquisas quantitativas e seus respectivos limites, há muitas intervenções mais destacadas, como a relevância do currículo, ou seja, importaria mais - que acontece quando a porta da sala de aula se fecha (HATTIE, 2002).

- Numa visão abrangente da literatura, a qualidade tende a ser assimetricamente distribuída dentro da escola:

- As turmas de maior aproveitamento tendem a receber os melhores professores (bons docentes preferem bons estudantes) e, tendo em vista o hiato entre o currículo planejado e o currículo implementado, têm mais oportunidades de aprendizagem. As expectativas de pais e colegas também são positiva ou negativamente afetadas, conforme o nível da turma.

${ }^{6} \mathrm{CF}$. CRAHAY, 2002. 
- Os alunos são escolhidos predominantemente pelo critério do mérito, que é basicamente o rendimento anterior, mas que ratifica as diferenças sociais e pode segregar os alunos ao nível da sala de aula. Daí a tendência à associação das turmas mais e menos "adiantadas" à raça, etnia e SSE.

- Segundo a maior parte da pesquisa, a formação de turmas homogêneas aumenta o hiato de aproveitamento entre as mais e menos "fortes" (RIORDAN, 2004).

Algumas questões permanecem, como a possibilidade de, misturando os alunos mais e menos "capazes", baixar o nível de ensino-aprendizagem e passar um rolo compressor sobre todos, impedindo ou dificultando a excelência. Outra pergunta se refere ao que fazer. Crahay (2002), resenhando pesquisas de dois continentes, Europa Ocidental e América do Norte, conclui:

- Não há vantagem confirmada para as turmas homogêneas, sendo que parte dos estudos dá ligeira vantagem às classes heterogêneas.

- Quanto à regressividade dos efeitos, pode-se recear que, fora de condições experimentais rigorosas, os alunos reputados "fortes" se beneficiem de ensino quantitativa e qualitativamente superior ao dos "fracos".

- Quanto às alternativas para a ação, - O caminho da aprendizagem individualizada tem evidência de fracos benefícios.

- No entanto, a organização flexível de grupos homogêneos constituídos em função do nível de domínio de uma competência específica traz efeitos positivos inegáveis.
Portanto, a proposição de Crahay (2002) é a da constituição de escolas sem turmas organizadas por idade e série. $\bigcirc$ critério seria a agregação temporária dos alunos por níveis de competências equivalentes, segundo módulos hierarquizados. Ou seja, seriam maximizadas as interações entre os alunos e provavelmente a heterogeneidade, de tal maneira que quem ocupasse alto status em um módulo e grupo poderia não ocupá-lo em outro. Entretanto, a viabilidade desta alternativa em escolas de grande porte e extensas redes de estabelecimentos pode ser duvidosa, ainda mais com níveis muito heterogêneos da formação de professores. De qualquer modo, o conjunto das pesquisas de diferentes orientações teóricas e metodológicas aconselha cautela em face da formação de grupos homogêneos, visto que existe uma persistente tendência de as origens sociais e o capital cultural e social atraírem condições educacionais correspondentes. É preciso atenção ao processo acumulativo pelo qual os rios correm para o mar.

\section{Concluindo}

Por mais reduzida que seja a influência da escola no cômputo geral, é possível atuar sobre os fatores acima e outros, modelando-a de modo a oferecer uma educação de qualidade para todos. A escola e os educadores não só têm o seu protagonismo, como também a sua margem de influência é mais ampla nos países em desenvolvimento que nos desenvolvidos. Por isso, os educadores e a educação podem fazer diferença. Para tanto é indispensável saber como. 


\section{Referências}

ABRAMOVAY, M. et al. Escolas inovadoras: experiências bem-sucedidas em escolas públicas. Brasília, DF: UNESCO, 2003.

ARMITAGE, J. et al. School quality and achievement in rural Brazil. Washington, DC: The World Bank, 1986.

BARRÈRE, A.; SEMBEL, N. Sociologie de l'éducation. Paris: Nathan, 2002.

BRANDÃO, Z.; BAETA, A. M. B.; ROCHA, A. D. C. O estado da arte da pesquisa sobre evasão e repetência no ensino de $1^{\circ}$ grau no Brasil (1971-1981). Revista Brasileira de Estudos Pedagógicos, Brasília, DF, v. 64, n. 147, p. 38-69, maio/ago. 1983.

CAMPOS, M. M. (Org.). Consulta sobre qualidade da educação na escola: relatório técnico final. São Paulo: Campanha Nacional pelo Direito à Educação, Fundação Carlos Chagas, 2002.

CARLSSON, B. A. Achieving educational quality: what schools teach us: learning from Chile's P900 primary schools. Santiago, Chile: CEPAL, 2000.

CARNOY, M.; GOVE, A. K.; MARSHALL, J. H. Explaining differences in academic achievement in Latin America: qualitative evidence from Brazil, Chile and Cuba.

Stanford: Stanford University, 2003. Mimeografado.

CASASSUS, J. A escola e a desigualdade. Brasília, DF: Plano, 2002.

CASTRO, C. M. et al. Determinantes de la educación en América Latina: acceso, desempeño y equidad. Rio de Janeiro: Fundação Getúlio Vargas, 1984.

CEPAL; UNESCO. Financiamiento y gestión de la educación en América Latina y el Caribe: versión preliminar: trigésimo período de sesiones de la CEPAL. San Juan, Puerto Rico: CEPAL, UNESCO, 2004.

COHN, E.; ROSSMILLER, R. A. Research on effective schools: implications for less developed countries. Comparative Education Review, Chicago, v. 31, n. 3, p. 377-399, ago. 1987.

COLEMAN, J. S. The adolescent subculture and academic achievement. American Journal of Sociology, Washington, DC, v. 65, n. 4, p. 337-347, 1960.

. The adolescent society: the social life of the teenager and its impact on education. New York: The Free Press of Glencoe, 1963.

COLEMAN, J. S. et al. Equality of educational opportunity. Washington, DC: US Government Printing Office, 1966.

COSTA, J. A. Imagens organizacionais da escola. Porto: Asa, 1996. 
COSTA, M. O rendimento escolar no Brasil e a experiência de outros países. São Paulo: Loyola, 1990.

CRAHAY, M. Poderá a escola ser justa e eficaz?: da igualdade das oportunidades à igualdade dos conhecimentos. Lisboa: Instituto Piaget, 2002.

DALE, R. The state and the governance of education: an analysis of the restructuring of the state-education relationship. In: HALSEY, A. H. et al. (Org.). Education: culture, economy, and society. Oxford: Oxford University Press, 1997. p. 273-282.

DARLING-HAMMOND, L. Restructuring schools for student success. In: HALSEY, A. H. et al. (Org.). Education: culture, economy, and society. Oxford: Oxford University Press, 1997. p. 332-337.

DEBARBIEUX, E. Violência nas escolas: divergências sobre palavras e um desafio político. In: DEBARBIEUX, E.; BLAYA, C. (Org.). Violência nas escolas: dez abordagens européias. Brasília, DF: UNESCO, 2002.

DEBARBIEUX, E.; BLAYA, C. (Org.). Violência nas escolas: dez abordagens européias. Brasília: UNESCO, 2002.

DUBET, F. Le déclin de l'institution. Paris: Sevil, 2002.

DUBET, F. Sociologia da experiência. Lisboa: Instituto Piaget, 1996.

DUBET, F.; MARTUCCELLI, D. À l'école: sociologie de I'experience scolaire. Paris: Seuil, 1996.

ELHAV, M. Effects of change in the recapture provision on equity of education funding: evidence from Alberta. Journal of Education Finance, Reston, Virginia, n. 24, p. 206219, Autumn 1998.

ESTÊVÃO, C. V. Educação, justiça e autonomia: os lugares da escola e o bem educativo. Porto: Asa, 2004.

FARRELL, J. P. International lessons for school effectiveness: the view from the developing world. In: FARRELL, J. P.;

OLIVEIRA, J. B. A. (Org.). Teachers in developing countries: improving effectiveness and managing costs. Washington, DC: The World Bank, 1993.

FULLER, B. What school factors raise achievement in the Third World? Review of Educational Research, Washington, DC, v. 57, n. 3, p. 255-292, Fall 1987.

GOMES, C. A.; CASTRO, P. E. M. A gestão do espaço no ensino médio público. Ensaio: avaliação e políticas públicas em educação: revista da Fundação Cesgranrio, Rio de Janeiro, v. 11, n. 38, p. 5-14, jan./mar. 2003. 
HANUSHEK, E. A. et al. Making schools work: improving performance and controlling costs. Washington, DC: The Brookings Institution, 1994.

HARBISON, R. W.; HANUSHEK, E. A. Educational performance of the poor: lessons from rural Northeast Brazil. Oxford: Oxford University Press, The World Bank, 1992.

HARLING-HAMMOND, L. Restructuring schools for student success. In: HALSEY, A. H. et al. (Org.). Education: culture, economy, and society. Oxford: Oxford University Press, 1997. p. 332-338.

HATTIE, J. A. C. Classroom composition and peer effects. International Journal of Educational Research, Exeter, v. 37, p. 449-481, 2002.

JONSSON, J. O.; ERIKSON, R. Understanding educational inequality: the Swedish experience. L'Année Sociologique, Paris, v. 50, n. 2, p. 345-382, 2000.

LOURENÇO FILHO, M. B. Aperfeiçoamento do magistério. Revista Brasileira de Estudos Pedagógicos, Rio de Janeiro, v. 25, n. 78, p. 39-54, abr./jun. 1960.

MALDI, R. M. N.; GOMES, C. A. O financiamento do ensino médio público ao nível escolar: o patinho feio ainda à espera de se tornar cisne. Ensaio: avaliação e políticas públicas em educação: revista da Fundação Cesgranrio, Rio de Janeiro, v. 11, n. 40, p. 314-332, jul./set. 2003.

MARION, R.; FLANIGAN, J. Evolution and punctuation of theories of educational expenditure and student outcomes. Journal of Education Finance, Reston, Virginia, v. 26, n. 2, p. 239-258, Winter 2001.

MELLA, O. et al. Qualitative study of schools with outstanding results in seven Latin American countries. Santiago, Chile: UNESCO, Latin American Laboratory for Assessment of the Quality of Education, 2002.

MEURET, D. Établissement scolaires: ce qui fait la différence. L'Année Sociologique, Paris, v. 50, n. 2, p. 545-556, 2000.

MORTIMORE, P. Can effective schools compensate for society? In: HALSEY, A. H. et al. (Org.). Education: culture, economy, and society. Oxford: Oxford University Press, 1997. p. 476-488.

NAKIB, Y.; HERRINGTON, C. D. The political economy of K-12 education finance: the context of a fast growing large state. Journal of Education Finance, Reston, Virginia, $\mathrm{n}$. 23, p. 351-373, Winter 1998.

ORGANISATION FOR ECONOMIC CO-OPERATION AND DEVELOPMENT; UNESCO INSTITUTE FOR STATISTICS. Literacy skills for the world of tomorrow: further results from PISA 2000. Paris: OECD, UNESCO, 2003.

PEREIRA, J. B. B. A escola secundária numa sociedade em mudança: interpretação socioantropológica de uma experiência administrativa. São Paulo: Pioneira, 1969. 
RIORDAN, C. Equality and achievement. 2. ed. Upper Saddle River, New Jersey: Pearson Prentice Hall, 2004.

ROCHA, A. D. C. Contribuição das revisões de pesquisa internacional ao tema evasão e repetência no $1^{\circ}$ grau. Cadernos de Pesquisa, São Paulo, n. 45, p. 57-65, maio 1984.

SCHEERENS, J. Improving school effectiveness. Paris: UNESCO, International Institute for Educational Planning, 2000.

SCHEERENS, J.; BOSKER, R. The foundations of educational effectiveness. Oxford: Pergamon, 1997.

SCHIEFELBEIN, E.; SIMMONS, J. Os determinantes do desempenho escolar: uma revisão de pesquisas nos países em desenvolvimento. Cadernos de Pesquisa, São Paulo, n. 35 , p. 53-72, nov. 1980.

WAISELFISZ, J. J. Qualidade e recursos humanos nas escolas. Brasília, DF: MEC, Fundescola, 2000a.

. Recursos escolares fazem diferença? Brasília, DF: MEC, Fundescola, 2000b.

. Salas de aula, equipamentos e material escolar. Brasília, DF: MEC,

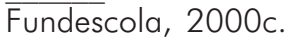

Tamanho da escola, ambientes escolares e qualidade do ensino. Brasília, DF: MEC, Fundescola, 2000d.

. Tamanho da turma: faz diferença? Brasília, DF: MEC, Fundescola, 2000e.

WEBER, M. Economy and society: an outline of interpretive sociology. New York: Bedminster Press, 1968.

WEICK, K. E. Educational organizations as loosely coupled systems. Administrative Science Quarterly, Ithaca, NY, n. 21,

p. 1-19, mar. 1976.

WILKINSON, I. et al. Discussion: modeling and maximizing peer effects in school. International Journal of Educational Research, Exeter, v. 37, p. 521-535, 2002.

WOESSMAN, L. Why students in some countries do better. Stanford: Hoover Institution, 2001. Disponível. em: <http://www.edmattersmore.org >. Acesso em: 2 abr. 2004.

Recebido em: 19/11/2004

Aceito para publicação em: 12/05/2005 